\title{
ANALISIS HUBUNGAN PERILAKU CARING DENGAN KINERJA PERAWAT PELAKSANA MENERAPKAN PRINSIP ETIK KEPERAWATAN DALAM ASUHAN KEPERAWATAN DI RUMAH SAKIT BHAYANGKARA MAPPA OUDANG MAKASSAR
}

\author{
Nurhayati \\ Jurusan Keperawatan, Poltekkes Kemenkes Pangkalpinang \\ Email: tyas776@gmail.com
}

\begin{abstract}
Analisys Relationship Caring Behavior to The Performance Nurse who Apply Ethical Principles at Bhayangkara Mappa Oudang Hospital. Nurse must apply ethical principles in performing nursing care, otherwise it can cause any harm to the client as a recipient of nursing care that can suffer injury or physical harm such as pain, disability or death, as well as the danger of such emotional feelings of helplessness or isolated ( CNA, 2004). Factors affecting the performance of nurses in applying the principles of ethics was nurse caring behaviour. This study was to identify the relationship caring behavior to the performance nurse who apply ethical principles at Bhayangkara Mappa Oudang Hospital, Makassar. The study design was descriptions correlation with cross sectional design. Total sample were 100 nurse. The results showed that the caring behavior $(p=0.000)$, respectful dimensions $(p=0.000)$, the assurance dimension of humanpresence $(\mathrm{p}=0.000)$ were significantly associated with performance applying ethical principles requires.
\end{abstract}

Keywords: Caring behavior, Performance, Ethics principles

\begin{abstract}
Abstrak: Analisis Hubungan Perilaku Caring dengan Kinerja Perawat Pelaksana Menerapkan Prinsip Etik Keperawatan dalam Asuhan Keperawatan di Rumah Sakit Bhayangkara Mappa Oudang Makassar. Kinerja perawat menerapkan prinsip etik penting untuk dilakukan mengingat perawat yang dalam melakukan asuhan keperawatan berperilaku tidak etik dapat menimbulkan kerugian bagi klien sebagai penerima asuhan keperawatan yaitu dapat mengalami injury atau bahaya fisik seperti nyeri, kecacatan atau kematian, serta bahaya emosional seperti perasaan tidak berdaya atau terisolasi (CNA, 2004). Faktor yang mempengaruhi kinerja perawat dalam menerapkan prinsip erik dalam asuhan keperawatan adalah perilaku caring perawat. Tujuan penelitian adalah mengidentifikasi hubungan perilaku caring dengan kinerja menerapkan prinsip etik keperawatan di Rumah Sakit Bhayangkara Mappa Oudang Makassar. Desain penelitian deskripsi korelasi dengan rancangan cross sectional. Sampel penelitian seeluruh perawat pelaksana yaitu 100 perawat. Hasil penelitian menunjukkan bahwa perilaku caring $(p=0,000)$, dimensi respectful $(p=0,000)$, dimensi assurance of humanpresence $(p=0,000)$ berhubungan secara signifikan dengan kinerja menerapkan perinsip etik.
\end{abstract}

Kata kunci: Perilaku caring, Kinerja, Prinsip etik

Rumah sakit adalah institusi pelayanan kesehatan yang menyelenggarakan pelayanan kesehatan perorangan secara paripurna, yang menyediakan pelayanan rawat inap, rawat jalan dan rawat darurat (UU RS no 44 tahun 2009). Seiring dengan perkembangan zaman, maka rumah sakit yang dulunya mempunyai misi charity (sosial) sekarang harus dapat menyeimbangkan antara misi bisnis yang berorientasi profit serta misi pengembangan ilmu pengetahuan dan teknologi tanpa melupakan misi sosialnya. Hal ini sesuai dengan ketentuan Departemen Kesehatan yang mengharuskan rumah sakit untuk mengalokasikan 20-30\% pendapatan rumah sakit bagi masyarakat kurang mampu (Depkes RI Dirjen Yanmed, 2005).

Kenyataan yang ada berlawanan dengan apa yang diharapkan oleh pemerintah karena berdasarkan telaah beberapa rumah sakit masih mengabaikan hal tersebut. Hasil survei yang dilakukan oleh Indonesian Corruption Wath (ICW) pada November 2009 di rumah sakit daerah Jabodetabek menyebutkan bahwa setidaknya ada 13 rumah sakit dari 23 rumah sakit yang masih memberikan pelayanan yang kurang memadai terhadap masyarakat kurang mampu, ditamba pula bahwa $74,9 \%$ dari 378 warga tidak mampu di wilayah Jabodetabek mengeluhkan layanan rumah sakit baik swasta 
maupun negeri yang dinilai sangat tidak memadai seperti sikap kurang manusiawi, diskriminatif, menelantarkan, dan menolak klien miskin kendati mengantongi surat keterangan tidak mampu serta meminta uang muka pembiayaan rumah sakit.

Peningkatan kinerja petugas kesehatan yang ada di rumah sakit mutlak dilakukan guna memperbaiki citra yang terbentuk di masyarakat dikarenakan kurang optimalnya pelayanan yang diberikan oleh pihak rumah sakit. Peningkatan kinerja juga perlu dilakukan tenaga keperawatan sebagai mayoritas tenaga kesehatan yang bekerja di rumah sakit (Gillies, 1994). Kinerja adalah perilaku kerja yang ditampkkan oleh orang-orang yang terlibat dalam suatu perusahaan dan dapat dinyatakan melalui sistem evaluasi kerja atau performance appraisal (Robbins, 2001).

Kinerja perawat menerapkan prinsip etik penting untuk dilakukan mengingat perawat yang dalam melakukan asuhan keperawatan berperilaku tidak etik dapat menimbulkan kerugian bagi klien sebagai penerima asuhan keperawatan yaitu dapat mengalami injury atau bahaya fisik seperti nyeri, kecacatan atau kematian, serta bahaya emosional seperti perasaan tidak berdaya atau terisolasi (CNA, 2004). Kerugian yang dialami klien tersebut akan menyebabkan ketidakpuasan klien yang pada akhirnya akan berdampak pada citra dan pendapatan rumah sakit (Okpara \& College, 2002). Sebaliknya perawat yang mengetahui tentang prinsip etik dan menerapkannya dalam memberikan asuhan keperawatan pada klien akan menimbulkan kepuasan kepada klien dan mempertahankan hubungan antara perawat, klien, dan petugas kesehatan lain sehingga klien merasa yakin akan mendapatkan pelayanan kesehatan yang aman dan berkualitas (Malau, 2008).

Faktor yang mempengaruhi kinerja perawat adalah dalam menerapkan prinsip erik dalam asuhan keperawatan adalah perilaku caring perawat. Caring adalah komponen penting dalam keperawatan dan merupakan inti dalam praktek keperawatan karena mengandung nilainilai humanistic, menghormati kebebasan manusia terhadap suatu pilihan, menekankan pada pada peningkatan kemampuan dan kemandirian, peningkatan pengetahuan dan menghargai setiap manusia (Tomey, 1994). Perawat yang mempunyai nilai dan jiwa caring akan mempunyai perilaku kerja yang sesuai dengan prinsip etik dikarenakan kepedulian perawat yang memandang klien sebagai makhluk humanistic sehingga termotivasi untuk memberikan pelayanan keperawatan yang bermutu tinggi.
Hasil studi pendahuluan dengan menyebarkan kuesioner yang dilakukan pada tanggal 30 April 2015 terhadap 20 klien tentang kinerja etik perawat menunjukkan bahwa 30\% klien masih merasakan bahwa perawat belum berperilaku etik dalam melakukan asuhan keperawatan terhadap klien. Hasil yang hampir sama didapatkan dari hasil penelitian Suhartati (2002) tentang faktor-faktor yang berhubungan dengan penerapan etik profesi keperawatan dalam asuhan keperawatan di Rumah Sakit G di Makassar menemukan bahwa $50,4 \%$ berperilaku etik dalam memberikan asuhan keperawatan dan 49,6\% berperilaku tidak etik dalam memberikan asuhan keperawatan.

Hasil wawancara dengan kasie keperawatan tentang fungsi pembinaan etik perawat menyebutkan bahwa setiap terjadi pelanggaran etik keperawatan oleh perawat pelaksana dilakukan pembinaan oleh atasan langsung dalam hal ini oleh kepala ruangan dan dilaporkan pada kasie keperawatan. Pelaporan pelanggaran etik dilakukan oleh pasien, rekan kerja atau atasan. Pelaporan pelanggaran etik selama ini lebih banyak dilakukan oleh pasien kepada pihak managerial maupun kepala ruangan. Rekan kerja yang mengetahui pelanggara etik yang dilakukan oleh teman satu shift cenderung menutupi sehingga tidak banyak kasus pelanggaran etik yang sampai pada atasan atau kasie keperawatan. Data mengenai pelanggaran disiplin perawat pelaksana seperti terlambat, bekerja dengan sistem paruh waktu dengan rekan satu shift atau pelanggaran terhadap peraturan rumah sakit yang ditangani oleh kepala ruangan tidak dilaporkan pada kasie keperawatan sehingga kasie keperawatan tidak mempunyai rekapitulasi pelanggaran yang terjadi.

Fenomena-fenomena yang terjadi di Rumah Sakit Bhayangkara Mappa Oudang Makassar ini menunjukkan bahwa kinerja perawat dalam menerapkan prinsip etika dalam asuhan keperawatan belum optimal, sedangkan dari kajian dan temuan ilmiah menujukkan bahwa perilaku caring perawat memiliki hubungan dengan kinerja perawat dalam menerapkan prinsip etik dalam asuhan keperawatn. Maka peneliti tertarik untuk meneliti "Hubungan perilaku caring dengan kinerja perawat pelaksana menerapkan prinsip etik keperawatan dalam asuhan keperawatan di Rumah Sakit Bhayangkara Mapp Oudang Makassar". 


\section{METODE PENELITIAN}

Penelitian ini menggunakan jenis penelitian observasional analitik dengan menggunakan desain Cross Sectional Study (metode potong lintang). Penelitian ini dimaksudkan untuk mengetahui hubungan perilaku caring dengan kinerja perawat pelaksana menerapkan prinsip etik keperawatan dalam asuhan keperawatan di Rumah Sakit Bhayangkara Mappa Oudang Makassar.

Penelitian ini dilaksanakan di Rumah Sakit Bhayangkara Mappa Oudang Makassar dengan pertimbangan belum pernah diadakan penelitian serupa.

Populasi dalam penelitian ini adalah seluruh perawat pelaksana baik laki-laki maupun perempuan yang berjumlah 102 perawat.

Sampel adalah sebagian yang mewakili populasi. Teknik penentuan jumlah sampel dalam penelitian ini menggunakan total sampling yaitu semua populasi terjangkau yang memnuhi kriteria inklusi menjadi sampel penelitian, dengan demikian sampel dalam penelitian ini adalah semua perawat pelaksana baik laki-laki maupun perempuan di instalasi rawat inap. Jumlah total perawat pelaksana tersebut 102 perawat tetapi hanya 100 orang yang menjadi sampel karena 2 orang perawat sementara cuti melahirkan pada saat penelitian dilakukan sehingga tidak termasuk dalam kriteria inklusi.

Data diperoleh berdasarkan wawancara langsung kepada responden dengan menggunakan kuesioner dan informend consent yang telah disediakan.

Data yang telah dikumpulkan diolah dengan menggunakan bantuan komputer. Selanjutnya dianalisis dengan menggunakan analisis univariat untuk mendapatkan gambaran secara deskriptif dari tiap-tiap variabel yang diteliti dan analisis bivariat untuk menguji hipotesis dilakukan dengan menggunakan Chi Square dengan tujuan untuk mengetahui hubungan variabel independen dengan dependen.

\section{HASIL}

\section{Karakteristik Sampel}

Karakteristik sampel dapat dilihat pada tabel 1 menunjukkan bahwa dari 100 responden yang berjenis kelamin perempuan sebanyak 72 perawat (72\%), pendidikan DIII Keperawatan sebanyak 84 perawat $(84 \%)$ dan yang berstatus pernikahan menikah yaitu sebanyak $85(85 \%)$.
Tabel 1. Distribusi Frekuensi Perawat Pelaksana Menurut Jenis Kelamin, Tingkat Pendidikan dan Status Pernikahan

\begin{tabular}{lcc}
\hline \multicolumn{1}{c}{ Variabel } & Frekuensi & $\begin{array}{c}\text { Presentase } \\
(\boldsymbol{\%})\end{array}$ \\
\hline Jenis Kelamin & & \\
Laki-laki & 28 & 28 \\
perempuan & 72 & 72 \\
\hline Tingkat & & \\
pendidikan & 84 & 84 \\
DIII & 16 & 16
\end{tabular}

Keperawatan

S1 keperawatan

\begin{tabular}{lll} 
Status & & \\
Pernikahan & 15 & 15 \\
Tidak menikah & 85 & 85 \\
Menikah & & \\
\hline
\end{tabular}

Sumber: Data Primer, 2015

\section{Perilaku Caring}

Tabel 2 menunjukkan tentang pelaksanaan perilaku caring dengan nilai rata-rata adalah 52,88, dengan standar deviasi 5,341. Nilai terendah adalah 41 dan nilai tertinggi adalah 64 . Dari hasil estimasi interval dapat disimpulkan bahwa 95\% diyakini bahwa rata-rata nilai perilau caring perawat pelaksana adalah antara 51,82 sampai dengan 53,94. Berdasarkan hasil ini, nilai rata-rata perilaku caring perawat pelaksana berada pada rentang tingkat kepercayaan 95\%, sehingga dapat disimpulkan bahwa pelaksanaan perilaku caring perawat pelaksana di Rumah Sakit Bhayangkara Mappa Oudang Makassar tergolong baik.

Tabel 2.Distribusi Rata-Rata Pelaksanaan Perilaku Caring (Respectful dan assurance of human presence) Perawat Pelaksana

\begin{tabular}{lcccc}
\hline Variabel & $\begin{array}{c}\text { Mean } \\
\text { Median } \\
\text { Modus }\end{array}$ & SD & $\begin{array}{c}\text { Minimum } \\
- \\
\text { Maksimum }\end{array}$ & $\begin{array}{c}\mathbf{9 5 \%} \\
\text { CI }\end{array}$ \\
\hline Perilaku & 32,88 & 5,341 & 41 & 51,82 \\
caring & 52 & & 64 & - \\
& 52 & & & 53,94 \\
\hline Respectfult & 25,94 & 2,785 & 20 & 25,39 \\
& 26 & & 32 & - \\
& 23 & & & 26,49 \\
\hline Assurance of & 26,94 & 3,206 & 20 & 26,30 \\
human & 28 & & 32 & - \\
presence & 28 & & & 27,58 \\
\hline Sum
\end{tabular}

Sumber: Data Primer, 2015

Hasil analisis data dari sub variabel perilaku caring dimensi assurance of human presence perawat pelaksana menujukkan nilai 
rata-rata adalah 26,94 dengan standar deviasi 3,206 . Nilai terendah adalah 20 dan nilai tertinggi adalah 32. Dari hasisl estimasi interval dapat disimpulkan bahwa $95 \%$ diyakini bahwa rata-rata nilai perilaku caring dimensi assurance of human presence perawat pelaksana di Rumah Sakit Bhayangkara Mappa Oudang Makassar tergolong sangat baik.

\section{Kinerja Perawat Pelaksanaan Menerapkan Prinsip Etik Keperawatan Dalam Asuhan Keperawatan}

Tabel 3 Penilaian perawat pelaksana tentang kinerja menerapkan prinsip etik keperawatan dalam asuhan keperawatan menunjukkan bahwa nilai rata-rata adalah 115,49 deviasi 10,972. Nilai terendah 90 dan nilai tertinggi 138 . Dari hasil estimasi interval dapat disimpulkan bahwa 95\% diyakini bahwa rata-rata nilai kinerja perawwat pelaksana menerapkan prinsip etik adalah antara 113,31 sampai dengan 117,67.

Nilai rata-rata kinerja perawat pelaksana menerapkan prinsip etik berada pada rentang tingkat kepercayaan 95\% sehingga dapat disimpulkan bahwa perawat pelaksana di Rumah Sakit Bhayangkara Mappa Oudang Makassar mempunyai kinerja dalam menerapkan prinsip etik yang baik.

4. Hubungan Perilaku Caring (Respectful Dan Assurance Of Human Presence) Dengan Kinerja Perawat Pelaksana Menerapkan Prinsip Etik Dalam Asuhan Keperawatan

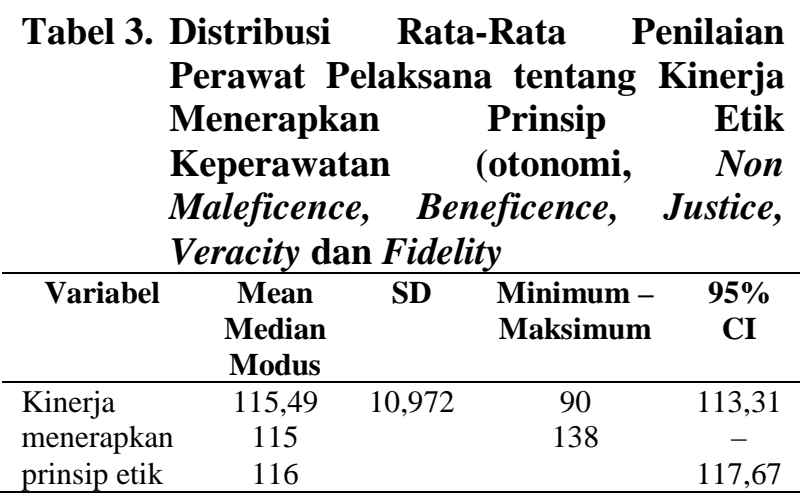

Sumber: Data Primer, 2015

Tabel 3 menunjukkan hasil analisis yang didapatkan untuk variabel independen perilaku caring dengan variabel dependen kinerja perawat pelaksana menerapkan prinsip etik dalam asuhan keperawatan diperoleh $\mathrm{r}=0,678$. Dimensi respectful didapatkan nilai $\mathrm{r}=0,561$. Dimensi assuance of human presence didapatkan hasil nilai $r=0,642$. Hal ini menunjukkan bahwa perilaku caring, dimensi respectful dan dimensi assurance of human ada hubungan yang signifikan dengan kinerja perawat pelaksana menerapkan prinsip etik dalam asuhan keperawatan di Rumah Sakit Bhayangkara Mappa Oudang Makassar dengan kekuatan hubungan kuat dan berpola positif.

\section{PEMBAHASAN}

1. Hubungan Perilaku Caring dengan Kinerja Perawat Pelaksana Menerapkan Prinsip Etik Dalam Asuhan Keperawatan

Caring merupakan konsep sentral atau inti bagi keperawatan akan tetapi caring tidak bisa dianggap sebagai paradigma yang unik bagi profesi keperawatan karena profesi kesehatan lain juga menganggap caring sebagai bagian integral dari kemampuannya yang terdiri atas pengetahuan dan keterampilan. Caring masih merupakan konsep yang abstrak dan masih sulit untuk dipahami. Oleh sebab itu sampi sekarang masih menjadi perdebatan dan menjadi subjek yang menarik dalam penelitian guna mencari jawaban atas pertanyaan dan perdebatan tersebut.

Watson (2002) mendefinisikan caring sebagai imu, dimana perspektif ilmu caring didasarkan pada ontologi hubungan dimana semua yang terlibat berada dalam suatu hubungan, bersatu dan mempunyai keterkaitan antara satu dengan yang lain. Perilaku caring menurut Watson adalah proses yang dilakukan oleh perawat yang meliputi pengetahuan, tindakan dan dideskripsikan sebagai 10 faktor yang digunakan dalam praktek keperawatan di beberapa seting klinik yang berberda.

Leininger mendeskripsikan caring dari dimensi budaya. Perilaku caring menurut pendapat Leininger (1988) adalah aktivitas perawat yang penuh dengan keterampilan, suatu proses dan pengambilan keputusan yang berhubungan dengan membantu klien yang merefleksikan atribut sikap (prinsip etim perawat) seperti empati, mendukung, belas kasih, melindungi dan hal-hal lain tergantung kebutuhan, nilai, masalah, nilai dan tujuan yang ingin dicapai oleh individu ataupun kelompok yang dibantu perawat.

Kesimpulan yang dapat diambil dari beberapa pernyataan pakar di atas adalah caring terdiri atas dua aspek yaitu berupa tindakan nyata perawat dalam melakukan peran dan tugasnya dalam memberika asuhan keperawatan pada klien dan aspek afektif perawat seperti perasaan cinta, 
altruisme, belas kasih, kehangatan serta perasaan lain yang mendasari perawat melakukan tindakan caring kepada klien.

Definisi perilaku caring dalam penelitian ini adalah pernyataan perawat pelaksana tentang perilaku caring yang dilakukan pada saat melakukan asuhan keperawatan yang terdiri dari dimensi respectful dan assurance of human presence. Dimensi ini mengadopsi dari 5 dimensi perilaku caring yang dikategorikan oleh Wolf (1994 dalam Watson, 2009) dan oleh peneliti hanya dipilih 2 dimensi yang mempunyai keterkaitan dan hubungan dengan kompetensi dan perasaan afektif kinerja menerapkan prinsip etik.

Hasil analisis univariat didapatkan gambaran bahwa peerilaku caring yang dilakukan oleh perawat pelaksana di Rumah Sakit Bhayangkara Mappa Oudang Makassar tergolong baik. Hasil analisis hubungan perilaku caring dengan kinerja perawat pelaksana menerapkan prinsip etik dalam asuhan keperawatan didapatkan $p$ value $=0,000$ lebih kecil dari nilai alpha 0,05 . Hasil ini menunjukkan terdapat hubungan yang signifikan antara perilaku caring dengan kinerja perawat pelaksana menerapkan prinsip etik.

Penelitian yang ada selama ini lebih memfokuskan pada hubungan atau pengaruh caring terhadap klien yaitu terhadap peningkatan kepuasan klien (Wolf, Colahan, Costello, Warwick, Ambrose \& Giardino, 1998) serta penurunan hari rawat. Belum banyak hasil penelitian yang dilakukan dan dipublikasikan mengenai hubungan perilaku caring dengan kinerja perawat. Swanson (dalam Watson, 2009) melakukan meta analisis terhadap 130 penelitian keperawatan yang mengidentifikasi bahwa dampak perilaku caring terhadap perawat adalah timbulnya rasa cinta terhadap keperawatan sehingga perawat akan berusaha meningkatkan pengetahuan, menghargai kehidupan dan kematian, menunjukkan integritas, keutuhan, dan harga diri serta perasaan puas dapat membantu klien mencapai kesehatan dan kesejahteraan. Dampak perilaku caring yang dirasakan oleh perawat ini yang diharapkan menimbulkan motivasi kerja perawat untuk mengoptimalkan kinerjanya termasuk kinerja perawat pelaksana menerapkan prinsip etik eperawatan dalam asuhan keperawatan.

Hal yang menarik mengenai caring dikemukakan oleh Pepin (1992 dalam Petterson $\&$ Bredow, 2008). Caring dinyatakan dalam 2 dimensi yaitu cinta (love) dan pekerjaan (labour). Cinta berupakonsep-konsep afektif seperti altruisme, belas kasih, emosi, keberadan, hubungan, pemeliharaan dan kenyamanan. Sedangkan caring sebagai pekerjaan berarti peran, fungsi, pengetahuan dan tugas perawat dalam melaksanakan asuhan keperawatan pada pasien. Hal yang dapa disimpulkan dari pernyataan Pepin adalah dalam melaksanakan peran, fungsi dan tugas sebagai perawat disamping berdasarkan pada pengetahun dan keterampilan keperawatan juga harus berlandaskan pada perasaan cinta perawat terhadap pekerjaan maupun klien yang meliputi altruism dan belas kasih sehingga perawat mampu mengendalikan emosi atau perasaan yang tidak menyenangkan lainnya, mampu menjalin hubungan yang baik dengan klien, membuat klien merasa nyaman dalam kondisi sakitnya, serta mampu membantu klien memenuhi kebutuhan dasarnya.

Perilaku caring pada dasarnya merupakan interaksi antara perawat dan klien sebagai individu yang dikenal sebagai proses klinik caring (clinical caring process) dimana caring merupakan tindakan keperawatan yang menyebabkan perawat dan klien membentuk suatu hubungan yang terus menerus dan berkesinambungan dalam proses perawatan klien sehingga pada akhirnya akan menimbulkan rasa saling memahami satu sama lain antara klien dan perawat (Duffy, 2005).

Kesimpulan yang dapat diambil dari pakar tersebut mengenai caring sebagai suatu proses interaksi antara perawat dan klien yang memerlukan kerja sama keddua belah pihak, dan agar klien sebagai penerima asuhan keperawatan dapat kooperatif maka perawat diharapkan dapat mempunyai kemampuan komunikasi terapeutik dan pengetahuan serta keterampilan dalam melakukan tindakan asuhan keperawatan yang memadai sehingga menimbulkan keperacayaan klien kepada perawat. Hal ini sesuai dengan hasil penelitian yang dilakukan Gay (1999) dan Kimble (2003) yang menyatakan bahwa aspek emosional sama pentingnya dengan aspek teknik yang ditunjukkan perawat dalam melakukan asuhan keperawatan. Aspek teknik yang dianggap klien sebagai perilaku caring perawat adalah perawat tahu apa yang dilakukan untuk memberikan tindakan keperawatan dan pengobatan tepat waktu. Sedangkan aspek emosianal yang dipersepsika oleh klien yaitu mengajarkan pada klien apa yang mereka butuhkan untuk diketahui yaitu perawat dapat menjawab pertanyaan kloen secara jelass dan dapat memberikan informasi yang dibutuhkan klien dengan bahasa yang mudah dimengerti klien. 
Peneliti berpendapat, dengan teridentifikasinya perilaku caring perawat pelaksana di Rumah Sakit Bhayangkara Mappa Oudang Makassar yang tergolong baik maka potensi untuk pelaksanaan pelayanan keperawatan Rumah Sakit Bhayangkara Mappa Oudang Makassar akan semakin baik juga. Hal ini perlu menjadi pertimbangan pihak manager keperawatan dan manager rumah sakit untuk mempertahanlan perilaku caring yang baik dengan cara menciptakan lingkungan yang mendukung dan dapat menimbulkan budaya perilaku caring. Upaya yang dapat dilaksanakan yaitu dengan role model atasan dalam berperilaku caring.

Hasil analisis ditinjau dari dua dimensi dalam perilaku caring terlihat bahwa kedua dimensi ini berhubungan secara signifikan dengan kinerja perawat pelaksana menerapkan prinsip etik dan pola hubungan positif, dimana untuk dimensi respectful kekuatan hubungan $\mathrm{r}=0,561 \quad(p$ value $=0,000)$, sedangkan untuk dimensi assurance of human presence kekuatan hubungan $\mathrm{r}=0,642$ ( $p$ value $=0,000)$. Hasil ini sesuai dengan pendapat yang dikemukakan oleh Aquiza(1997 dalam Malau, 2008) bahwa perawat yang mempunyai rasa menghormati terhadap keberadaan manusia maka akan memandang klien sebagai individu yang unik dan menganggap bahwa klien berhak mendapatkan perlakuan yang sesuai dengan martabatnya sebagai manusia sehingga perawat melakukan asuhan keperawatan dengan menerapkan prinsip etik seperti menghormati pilihan klien, tidak membeda-bedakan klien, mengizinkan klien berpartisipasi dalam perawatannya dan lain-lain. Pendapat ini diperkuat oleh pernyataan Potter \& Perry (2005) yang menyatakan bahwa hubungan caring yang terbentuk antara klien dan perawat membantu perawat untuk lebih mengenal klien secara individu yang unik sehingga perawat dapat menentukan tindakan keperawatan yang sesuai dan efektif bagi klien.

Lebih lanjut dijelaskan oleh Thiroux (1990 dalam Potter dan Perry, 2005) yang menyatakan bahwa respect dan assurance of human presence berarti semua orang tidak terkecuali perawat dalam memberikan asuhan keperawatan kepada klien harus menghargai dirinya sendiri dan orang lain termasuk kehidupan dan kematian. Kehidupan adalah hak dasar yang dimiliki oleh semua manusia dan merupakan sesuatu yang berharga bagi manusia, oleh karena itu perawat diwajibkan untuk melakukan segala upaya untuk mempertahankan kehidupan klien baik secara kuantitas maupun secara kualitas. Tindakan ini juga berarti menghargai perbedaan dan keunikan klien sebagai individu. Hal ini dapat dilakukan perawat jika perawat mempunyai pengetahuan tentang manusia, aspek tumbuh kembang, respon terhadap lingkungan yang terus berubah, keterbatasan dan kekuatan serta kebutuhankebutuhan manusia.

Perawat yang mempunyai pengetahu tentang manusia akan memandang klien sebagai makhluk humanistik yang harus diperlakukan sesuai dengan haknya dalam hal ini yaitu hak klien. Sesuai denga yang tertuang pada UU no 36 tahun 2009 tentang kesehatan yang menyebutkan bahwa tenaga kesehatan dalam melaksanakan tugasnya harus mematuhi standar profesi dan menghormati hak klien. CAN (2004:2008) mencantumkan hak klien terdiri atas keselamatan dan keamanan, hak atas informasi, hak untuk didengarkan dan hak untuk memilih pelayanan. Kode etik Rumah Sakit Indonesia (KODERSI, 2001) menyebutkan bahwa hak-hak asasi pasien adalah hak fundamental yang dimiliki pasien sebagai makhlik Tuhan yaitu hak untuk mendapatkan pelayanan kesehatan dan asuhan keperawatan yang bermutu sesuai dengan standar profesi kedokteran dan standar profesi keperawatan serta hal untuk menentukan nasib sendiri.

Peraturan-peraturan yang telah duaraikan di atas secara jelas melindungi klien terhadap pemenuhan hak-hak sebagai klien yang dimiliki yang berimplikasi pada tenaga kesehatan termasuk perawat untuk memberikan asuhan keperawatan sesuai dengan standar profesi dan erik. Penerapan prinsip etik universal dalam asuhan keperawatan membuat klien akan lebih kooperatif dan menimbulkan hubungan kerja sama yang baik antara perawat dan klien.

\section{SIMPULAN}

Hasil analisis chi square dengan confidence interval (CI) $95 \%$ dan $\alpha=0,05$ didapatkan untuk variabel independen perilaku caring dengan variabel dependen kinerja perawat pelaksana menerapkan prinsip etik dalam asuhan keperawatan diperoleh $\mathrm{r}=0,678$. Dimensi respectful didapatkan nilai $\mathrm{r}=0,561$. Dimensi assuance of human presence didapatkan hasil nilai $\mathrm{r}=0,642$. Hal ini menunjukkan bahwa perilaku caring, dimensi respectful dan dimensi assurance of human ada hubungan yang signifikan dengan kinerja perawat pelaksana menerapkan prinsip etik dalam asuhan keperawatan di Rumah Sakit Bhayangkara Mappa Oudang Makassar dengan kekuatan hubungan kuat dan berpola positif. 


\section{SARAN}

Bagi pimpinan rumah sakit memotivasi perawat pelaksana dalam mengoptimalkan kinerja menerapkan prinsip etik melalui pemberlakuan system remunerasi yang

\section{DAFTAR PUSTAKA}

Aiken. 2003. Legal, ethical, and political issue in nursing. Philadelphia: F.A. Davis Company.

Canadian Nurses Association. 2004. Every Day Ethics. Otawa: Author. https://www.cna.aiic.ca/CNA/document/pd f/publications/EverydayEthics_epdf (Diakses 18 Maret 2015)

2008.

Code of Ethics for Registered Nurses. Otawa:

Author. https://www.cna.aiic.ca/CNA/document/pd f/publications/code_of_Ethics_2008_epdf (Diakses 18 Maret 2015)

Departemen Kesehatan. Direktorat Jenderal Pelayanan kesehatan. 2005. Pedoman Penyusunan Rencana Bisnis dan Anggaran dan Penilaian Tingkat Kesehatan Rumah Sakit. Jakarta: Author.

Duffy.J.R. 2005. Annual Review of Nursing Education: Strategies for Teaching. Assesment and Program Planning. New York: Springer Publihing Company

Gay, S.m (Juli/Agustus 1999). Meeting cardiac patients' expectations of caring; Dimensions of critical care nursing. $D C C N$ Journal, 18(4), 46-50. Februari 2010. ABI/INFORM Global (Proquest) database.

Gillies.D.A. 1994. Nursing management: $a$ System Approach. Philadelphia: WB. Sounders Company.

Kode Etik Rumah Sakit. 2001. Hak-hak Asasi Pasien. The Author.

Leininger, M.M (1988). Care, the essence of nursing aand health. Detroit: wayne State Univercity Press

Malau. H. 2008. Ethical Principle Dimensions of Doctor and Nurses Toward Patient's Satisfaction. Jurnal Ekonomi dan Bisnis, 2 (1), 39-51. https://jurnal.pdii.lipi.go.id/admin.jurnal/2 1083951.pdf (Diakses 12 Maret 2015)

Okpara, J.O, \& College, B (2002). The influence of ethical climate types on job satisfaction berdasarkan pada tingkat pendidikan, masa kerja, pelatihan yang dimiliki, kompetensi dan tanggung jawab serta berdasarkan penilaian kinerja dengan memasukkan unsur caring sebagai salah satu kriteria penilaian kinerja perawat.

of it manager;implication for management practice and development in developing economy.

http://www.quationpro.com/acadec/onlinesurvey-research-this-survey-instrument-isfor-a-doctoral-dissertation-and-containsitems-from-four-prevviously-publishsurvey-instrument-thehtml (Diakses 12 Maret 2015).

Persatuan Perawat nasional Indonesia. 2010. Standar Profesi dan Kode Etik Keperawatan Indonesia. Jakarta: Authors.

Potter, p.a.,\& Perry, A.G. 2005. Fundamental of Nursing. Missouri: Elseivier Mosby.

Robbins, S.P. 2001. Organizational Behavior: Concept, Controversies, and Applications. Jakarta: Pearson Education Asia.

Suhartati. 2002. Faktor-faktor yang Berhubungan dengan Penerapan Etik Profesi Keperawatan Oleh Perawat Pelaksana Rumah Sakit Grestelina Makassar. Thesis. Fakultas Ilmu Keperawatan Universitas Hasanuddin. Tidak dipublikasikan

Tomey, A.M. 1994. Nursing theorist an their Work ( $3^{\text {rd }} e d$ ). Missouri: Mosby.

Undang-undang Republik Indonesia no 44 tahun 2009 tentang Rumah Sakit. no 36 Tahun 2009 tentang Kesehatan.

Watson, J. 2009. Assessing and Measuring Caring in Nursing and Health Sciences. Canada: Singer Publishing Company. 2002. Theory of Human Caring. http://www2.uchse.edu/son/caring/conten/ wet.asp (Diakses 14 Maret 2015)

Wolf, ZB.,\& Miller, P.A. 2003. Relationship Between Nurse Caring and Patient Satisfaction in Patient Undergoing Invasive Procedures. Journal Medsur Nursing. http://findarticles.com/p/articles/mi_m0FS S/is_6_12/ai_nl8616793/ (Diakses 14 maret 2015) 